\title{
What is the cell hydration status of healthy children in the USA? Preliminary data on urine osmolality and water intake
}

\author{
Jodi D. Stookey ${ }^{1, *}$, Bernie Brass ${ }^{1}$, Ava Holliday ${ }^{1}$ and Allen Arieff ${ }^{2}$ \\ ${ }^{1}$ Children's Hospital Oakland Research Institute, 5700 Martin Luther King Jr. Way, Oakland, CA 94609, USA: \\ ${ }^{2}$ Department of Medicine, University of California, San Francisco, CA, USA
}

Submitted 5 June 2011: Accepted 13 December 2011: First published online 27 January 2012

\begin{abstract}
Objective: Hyperosmotic stress on cells limits many aspects of cell function, metabolism and health. International data suggest that schoolchildren may be at risk of hyperosmotic stress on cells because of suboptimal water intake. The present study explored the cell hydration status of two samples of children in the USA.

Design: Cross-sectional study describing the urine osmolality (an index of hyperosmotic cell shrinkage) and water intake of convenience samples from Los Angeles (LA) and New York City (NYC).

Setting: Each participant collected a urine sample at an outpatient clinic on the way to school on a weekday morning in spring 2009. Each was instructed to wake, eat, drink and do as usual before school, and complete a dietary record form describing the type and amounts of all foods and beverages consumed after waking, before giving the sample.

Subjects: The children (9-11 years) in LA ( $n$ 337) and NYC ( $n$ 211) considered themselves healthy enough to go to school on the day they gave the urine sample. Results: Elevated urine osmolality $(>800 \mathrm{mmol} / \mathrm{kg}$ ) was observed in $63 \%$ and $66 \%$ of participants in LA and NYC, respectively. In multivariable-adjusted logistic regression models, elevated urine osmolality was associated with not reporting intake of drinking water in the morning (LA: OR $=2 \cdot 1,95 \% \mathrm{CI} 1 \cdot 2,3 \cdot 5$; NYC: $\mathrm{OR}=1 \cdot 8,95 \%$ CI $1 \cdot 0,3 \cdot 5)$. Although over $90 \%$ of both samples had breakfast before giving the urine sample, $75 \%$ did not drink water.

Conclusions: Research is warranted to confirm these results and pursue their potential health implications.
\end{abstract}

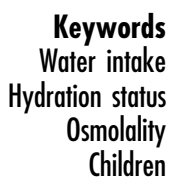

Cell hydration is integral to endocrine, immune, neural, cardiovascular, gastrointestinal, muscle and skeletal function. Changes in cell volume are required, for example, to mediate hormone release and response ${ }^{(1)}$, produce the electrical signals for neuron activation ${ }^{(2-5)}$ and regulate gene transcription and metabolic pathways ${ }^{(6,7)}$. When solute concentrations outside the cell are elevated, they create an osmotic force that draws water out of cells, limiting cell swelling and the processes that depend on cell volume change $\mathrm{e}^{(2,8-16)}$.

Cell dehydration is acutely associated with a wide variety of adverse outcomes in healthy adults and children, including insulin resistance ${ }^{(10)}$, an exaggerated cortisol ${ }^{(13)}$ and immune ${ }^{(17)}$ response to exercise, decreased sympathetic nervous activity ${ }^{(11)}$, impaired thermoregulation ${ }^{(18)}$ and impaired cognitive and physical performance ${ }^{(19,20)}$. In patients, cell dehydration is also associated with a wide variety of adverse outcomes, including diabetic keto$\operatorname{acidosis}^{(21)}$, neurological complications ${ }^{(22)}$, renal nephropathy $^{(23)}$, susceptibility to infection ${ }^{(24,25)}$, increased risk of red cell lysis in sickle cell anaemia ${ }^{(26,27)}$, nutrient malabsorption ${ }^{(28,29)}$ and mortality ${ }^{(30,31)}$.
Although much is known about the effects of cell dehydration in acute or extreme conditions (e.g. marathons) and critical illness, little is known about the longer-term public health impact of osmotic stress on cells, more generally. Data from the Duke EPESE (Duke site of the Established Populations for Epidemiologic Studies of the Elderly) study indicate that cell dehydration is associated with increased risk of incident diabetes ${ }^{(32)}$, frailty over 4 years and mortality over 8 years ${ }^{(33)}$ in community-dwelling older adults. The DONALD (Dortmund Nutritional and Anthropometric Longitudinally Designed) study in Germany has collected longitudinal data over 15 years on hydration status in free-living children ${ }^{(34)}$. Population-based, longitudinal studies are needed to determine if/how cell dehydration translates into disease risk in representative samples of non-acutely ill, free-living individuals.

In vivo, cell hydration status can be studied using urine osmolality. Cell shrinkage stimulates release of anti-diuretic hormone $(\mathrm{ADH})$, which signals the kidney to concentrate urine. Above a threshold osmolality of approximately $280 \mathrm{mmol} / \mathrm{kg}$, ADH is secreted in direct proportion to 
the osmotic force drawing water out of cells. As $\mathrm{ADH}$ levels increase, urine osmolality increases linearly until it reaches a maximum of approximately $1200 \mathrm{mmol} / \mathrm{kg}$ in children and younger adults ${ }^{(35,36)}$. Values over $800 \mathrm{mmol} / \mathrm{kg}$ are considered elevated ${ }^{(37-42)}$; values over $1000 \mathrm{mmol} / \mathrm{kg}$ are considered maximally concentrated. In healthy individuals, urine osmolality normally increases following overnight water restriction and decreases over the course of the day with water intake at meals ${ }^{(43)}$. Elevated urine osmolality at a point in time reflects cell shrinkage 2 to $4 \mathrm{~h}$ prior to the sample collection ${ }^{(44,45)}$. Elevated urine osmolality from a standardized $24 \mathrm{~h}$ urine collection, begun after the bladder is emptied, reflects sustained cell shrinkage over the $24 \mathrm{~h}$ collection period. Urine osmolality is less invasive and expensive and/or more sensitive to mild cell dehydration than other indicators, such as plasma osmolality, plasma $\mathrm{ADH}$, urine specific gravity and urine colour.

Although population-representative data on urine osmolality are rare ${ }^{(36)}$, available data suggest that cell dehydration may be prevalent in healthy, free-living children at school. Studies from Israel report that a majority of healthy Jewish children have a random urine osmolality over $800 \mathrm{mmol} / \mathrm{kg}$ on arrival at school ${ }^{(40)}$ and/or at noontime at school ${ }^{(40,41,46)}$. The elevated urine osmolality is attributed to insufficient water intake, because neighbouring Bedouin-Arab children, who live under the same arid conditions but have different drinking habits, do not have an elevated mean urine osmolality $(<800 \mathrm{mmol} / \mathrm{kg})^{(40,46)}$. Healthy children at school may be at risk of low water intake and cell dehydration because of limited access to drinking water and/or a phenomenon known as 'voluntary dehydration, ${ }^{, 47,48)}$

Data from other countries suggest that elevated urine osmolality may be prevalent in healthy children throughout the day. In Germany, the mean $24 \mathrm{~h}$ urine osmolality of a representative sample of children, aged 3-18 years, was $801 \mathrm{mmol} / \mathrm{kg}^{(36)}$. In Sweden, the mean $18 \mathrm{~h}$ urine osmolality of a convenience sample of twenty adolescents (12-17 years) was $841 \mathrm{mmol} / \mathrm{kg}^{(36)}$. In Germany, elevated urine osmolality is associated with lower total water intake and less water from beverages ${ }^{(49)}$.

The current prevalence of elevated urine osmolality in children in the USA is unknown. According to nationally representative data, however, US children have suboptimal water intake relative to recommendations ${ }^{(50)}$, and most US school districts do not have wellness policies that ensure the availability of drinking water ${ }^{(51)}$. In Los Angeles, access to drinking water is limited in some schools ${ }^{(52)}$.

The present study describes the urine osmolality of healthy children in two separate convenience samples from different regions of the USA, Los Angeles (LA) and New York City (NYC). To facilitate comparison of the results with the data from Israel, the study evaluated random urine osmolality on a weekday morning at a time of day when the participants were normally at school. To pursue whether elevated urine osmolality might be attributable to low water intake, the study tested for an association between elevated urine osmolality and lower total water intake, under temperate spring conditions, controlling for other hydration determinants. To determine if elevated urine osmolality might, furthermore, be attributable to drinking habits, the source of water intake (drinking water, water from other beverages or water from food) was also evaluated.

\section{Methods}

\section{Participants and study protocol}

The present cross-sectional study recruited healthy boys and girls, aged 9-11 years, living in LA and NYC in spring 2009. In each city, 50000 households were randomly selected from age-targeted mailing lists by a professional mailing company (Metro Mailing, Sacramento, CA, USA) to receive a postcard invitation to participate in a study of 'normal kidney function in healthy children'. Each postcard had a unique study id and invited only one eligible child to participate. Area of residence, age and general health were the only inclusion/exclusion criteria applied. Consistent with an expected response rate of $1 \%$ for postcard mailings (per the mailing company), 548 families in LA and 335 families in NYC responded to the mailing.

Respondents were mailed study materials, including child assent and parental consent forms, and instructions to choose a weekday morning when the child felt healthy enough to go to school to participate in the study. The child was instructed to wake as usual on the selected morning, eat, drink and do whatever is normal for him/ her before 08.30 hours, then go to a local Quest Diagnostics Patient Service Center clinic to void a clean catch sample in a cup between 08.30 and 09.30 hours and complete a questionnaire. The study materials did not disclose the study purpose to study cell hydration or urine osmolality. Respondents were offered a \$US 50 incentive for participation. Between 1 May and 15 June 2009, 337 children in LA and 211 in NYC completed the urine collection and study questionnaire. The maximum ambient temperatures in LA and NYC did not exceed $22^{\circ} \mathrm{C}$ during the study period. The study was approved by the Institutional Review Board at Children's Hospital \& Research Center Oakland where the study was coordinated. All study staff were trained in the protection of human research subjects. All study participants returned signed parental consent and child assent forms. All data records were collected and analysed in Oakland, CA, USA.

\section{Urine osmolality}

Urine osmolality was determined by freezing point depression osmometer at central Quest Diagnostics Laboratories (West Hills, CA, USA and Teterboro, NJ, USA). Consistent with the studies from Israel, elevated urine osmolality was defined as over $800 \mathrm{mmol} / \mathrm{kg}^{(40,42,46)}$. 


\section{Water intake}

Study participants recorded the type and quantity of all foods and/or beverages consumed in the morning before the urine collection on a diet record form with free spaces for reporting each item's time of consumption, name, description (e.g. low-fat $v$. whole milk, brand name, whole wheat $v$. white bread, margarine $v$. butter) and amount consumed. Only morning intake was recorded because urine osmolality reflects cell hydration since the previous void $(2-4 \mathrm{~h})^{(44,45)}$. The diet records were entered into Nutrition Diet Systems (NDS-R) software (1998-2008; Nutrition Coordinating Center, University of Minnesota, Minneapolis, MN, USA) by two trained research staff to estimate intake of drinking water, water from other beverages, water from food and total dietary water (the sum of drinking water, water from other beverages and water from food). Metabolic water was excluded from the total water intake calculation to focus on water intake behaviour or 'drinking habits'. One researcher was trained to use the NDS-R software in Minnesota by the Nutrition Coordinating Center. Drinking water was defined as tap, spring, mineral or unsweetened sparkling water. Other beverages were defined as any beverage other than drinking water, following the food group codes in the NDS-R software. Smoothies and milkshakes were considered beverages. Milk added to cereal was considered food.

If details about food or beverage type or portion size (such as the type or amount of milk added to cereal) were missing, systematic assumptions were applied, as there was no followup contact with families. To address potential reporting errors in the individual water intake estimates, dichotomous indicator variables were created to group participants.

Study participants were grouped with respect to the total amount of water reported as 'higher' $v$. 'lower' total water intake, defined using an arbitrary cut-off of $500 \mathrm{ml}$, equivalent to about $20 \%$ of the Adequate Intake of water for children 9-13 years ${ }^{(53)}$.

Participants were also grouped with respect to the reported source of water intake: drinking water, water from other beverages and water from food. Study participants who reported any drinking water, with or without food or other beverages, were identified as 'water drinkers'. Participants who reported any volume of any beverage other than drinking water, with or without food, were grouped in an 'other beverage' group. Participants who reported eating food, but had no beverage, were grouped in a 'food only' group. A 'no food or beverage' group reported no intake at all on the morning of the urine sample.

\section{Potential confounding factors}

The study questionnaire collected information about factors other than water intake that influence hydration status. Study participants self-reported their age, sex, body weight, height, general health and 'whether they noticed any skin changes, especially pimples' in the past 2 months. Recent skin changes are a validated index of pubertal hormones ${ }^{(54-56)}$ that modify ADH release ${ }^{(57,58)}$. The participants self-reported how many minutes they moved enough to sweat (like fast walking) or moved so fast that they got out of breath (like running) on the previous day. In sixth graders, self-reports of previous-day physical activity correlate with measurements made by accelerometer ${ }^{(59,60)}$. The participants recorded their use of medications and the time they went to sleep on the day before the urine collection. They recorded what time they woke on the morning of the urine collection. The hours of sleep were calculated to index the length of overnight fluid restriction. The NDS-R software generated estimates of the morning total energy intake and potential renal solute $\operatorname{load}(\mathrm{mmol}=5 \cdot 7 \times(\mathrm{g}$ of protein $)+(\mathrm{mg}$ of Na$/ 23)+(\mathrm{mg}$ of $\mathrm{K} / 39)+0.55 \times(\mathrm{mg}$ of $\mathrm{P} / 31))^{(61)}$. The latter is an index of 'osmotically effective' solute that cannot freely cross cell membranes and can, therefore, draw water out of cells by osmosis. Missing values for any of these factors were set to the sample mean value.

\section{Statistical analyses}

Statistical analyses were done using the STATA statistical software package version 9.2 (2006; StataCorp, College Station, TX, USA). To describe the prevalence of elevated urine osmolality and its relationship with water intake in the sample from each locale, data from the LA and NYC samples were analysed separately. All logistic and linear regression models adjusted for all of the covariates (age, sex, general health, body weight, height, recent skin changes, use of medications, physical activity level, sleep, and the morning total energy intake and potential renal solute load).

\section{Sample characteristics associated with elevated urine osmolality}

To identify variables that might confound relationships between elevated urine osmolality and water intake, multivariable logistic regression models tested for associations between each covariate listed above and the relative odds of elevated urine osmolality.

\section{Reported water intake by level of urine osmolality}

Linear regression models were used to describe how the raw (continuous) water intake variables related to urine osmolality before they were collapsed to group indicator variables. The models tested for associations between urine osmolality and total water, drinking water, water from other beverages and water from food, expressed in ml units.

\section{Relative odds of elevated urine osmolality by level of total water intake and source of water intake}

Logistic regression models tested for greater odds of elevated urine osmolality associated with a lower $v$. higher level of total water intake. Separate logistic regression models estimated the relative odds of elevated urine osmolality associated with different sources of water intake. The group that reported drinking water (the reference category) was compared with the groups that reported beverages other 
than drinking water, food only or no food or beverage. Additional logistic regression models also compared the group that reported drinking water with all of the other groups combined.

Mean urine osmolality by level of total water intake and source of water intake

It was not possible to estimate the relative odds of elevated urine osmolality associated with source of water, stratified by the level of total water. Only one out of thirteen participants from LA who reported over $500 \mathrm{ml}$ total water, without drinking water, had a urine osmolality below $800 \mathrm{mmol} / \mathrm{kg}$; only five out of twenty-five in NYC. Linear regression models therefore estimated the mean urine osmolality associated with drinking water $v$. not drinking water, stratified by the level of total water intake.

\section{Results}

\section{Sample characteristics}

Table 1 describes the samples from LA and NYC. The mean body weight and height were 39 (SD 10) $\mathrm{kg}$ and 144 (SD 9) $\mathrm{cm}$ in LA, and 39 (SD 12) $\mathrm{kg}$ and 143 (SD 11) $\mathrm{cm}$ in NYC.

Over $90 \%$ of both samples reported eating or drinking something in the hours before giving the urine sample (see Table 2). The mean reported total energy intake was 1348 (sD 816) kJ (322 (sD 195) kcal) for the sample from LA and 1319 (SD 808) kJ (315 (SD 193) kcal) for the sample from NYC. The mean osmotic load was 98 (SD 69) mmol for the sample from LA and 97 (sD 67) mmol for the sample from NYC. Total water intake ranged from zero to $1000 \mathrm{ml}$ for the sample from LA, with $88 \%$ of intakes below $500 \mathrm{ml}$ and a median intake of $260 \mathrm{ml}$. For the sample from NYC, total water intake ranged from zero to $990 \mathrm{ml}$, with $85 \%$ of intakes below $500 \mathrm{ml}$ and a median intake of $270 \mathrm{ml}$. Approximately $75 \%$ of both samples did not report drinking water. The majority reported a beverage other than water or food with no beverage.

\section{Prevalence of elevated urine osmolality}

Figure 1 describes the distribution of urine osmolality in both samples. Urine osmolality ranged from 99 to $1372 \mathrm{mmol} / \mathrm{kg}$ for participants from LA, with a mean of 827 (sD 250) mmol/kg. It ranged from 186 to $1259 \mathrm{mmol} /$ $\mathrm{kg}$, with a mean of 853 (SD 219) $\mathrm{mmol} / \mathrm{kg}$, for participants from NYC. The prevalence of elevated urine osmolality (over $800 \mathrm{mmol} / \mathrm{kg}$ ) was $63 \%$ in the sample from LA and $66 \%$ in the sample from NYC. Maximally concentrated urine (over $1000 \mathrm{mmol} / \mathrm{kg}$ ) was observed for $25 \%$ of participants from LA and $27 \%$ of participants from NYC.

\section{Sample characteristics associated with elevated urine osmolality}

In the sample from LA, elevated urine osmolality was significantly more likely among boys (adjusted OR $=2 \cdot 0$,
Table 1 Characteristics of the study samples: healthy children aged 9-11 years in Los Angeles (LA) and New York City (NYC), spring 2009

\begin{tabular}{|c|c|c|c|c|}
\hline \multirow[b]{2}{*}{ Characteristic } & \multicolumn{2}{|c|}{ LA ( $n$ 337) } & \multicolumn{2}{|c|}{ NYC $(n$ 211) } \\
\hline & $n$ & $\%$ & $n$ & $\%$ \\
\hline \multicolumn{5}{|l|}{ Age (years) } \\
\hline 9 & 87 & 26 & 61 & 29 \\
\hline 10 & 129 & 38 & 69 & 33 \\
\hline 11 & 121 & 36 & 81 & 38 \\
\hline \multicolumn{5}{|l|}{ Sex } \\
\hline Boys & 172 & 51 & 116 & 55 \\
\hline Girls & 165 & 49 & 95 & 45 \\
\hline \multicolumn{5}{|l|}{ Body weight $(\mathrm{kg})$} \\
\hline Not reported & 8 & 2 & 1 & 1 \\
\hline$<30$ & 67 & 20 & 39 & 18 \\
\hline 30-39 & 134 & 40 & 91 & 43 \\
\hline$\geq 40$ & 128 & 38 & 80 & 38 \\
\hline \multicolumn{5}{|l|}{ General health } \\
\hline Not reported & 25 & 7 & 32 & 15 \\
\hline Good & 36 & 11 & 18 & 9 \\
\hline Very good & 95 & 28 & 62 & 29 \\
\hline Excellent & 181 & 54 & 99 & 47 \\
\hline \multicolumn{5}{|c|}{ Recent skin changes } \\
\hline Not reported & 10 & 3 & 7 & 3 \\
\hline No & 201 & 60 & 122 & 58 \\
\hline Yes & 126 & 40 & 82 & 42 \\
\hline \multicolumn{5}{|c|}{ Medication use in the previous $24 \mathrm{~h}$} \\
\hline Not reported & 5 & 1 & 5 & 2 \\
\hline No & 255 & 76 & 165 & 78 \\
\hline Yes & 77 & 23 & 41 & 19 \\
\hline \multicolumn{5}{|c|}{$\begin{array}{l}\text { Moderate or vigorous physical activity } \\
\text { in the previous } 24 \mathrm{~h}(\mathrm{~min})\end{array}$} \\
\hline Not reported & 5 & 1 & 2 & 1 \\
\hline$<30$ & 150 & 45 & 110 & 52 \\
\hline$\geq 30$ & 182 & 54 & 99 & 47 \\
\hline \multicolumn{5}{|c|}{ Sleep in the previous $24 \mathrm{~h}(\mathrm{~h})$} \\
\hline Not reported & 4 & 1 & 1 & 1 \\
\hline $5-7$ & 6 & 2 & 9 & 4 \\
\hline $8-10$ & 286 & 86 & 173 & 82 \\
\hline $11-14$ & 41 & 12 & 28 & 13 \\
\hline
\end{tabular}

$95 \%$ CI $1 \cdot 2,3 \cdot 3, \quad P=0.005)$ and less likely among those reporting recent skin changes (adjusted OR $=0 \cdot 6$, $95 \%$ CI $0 \cdot 4,1 \cdot 0$ ). Similar trends for male gender and skin changes in the NYC sample were not statistically significant. The other covariates listed above were not significantly associated with elevated urine osmolality in either sample.

Reported water intake by level of urine osmolality Figure 2 illustrates the bivariate relationships between urine osmolality and reported water intake. Urine osmolality was inversely associated with total water intake in the sample from LA, but not in the sample from NYC. Urine osmolality was inversely associated with drinking water in both samples. Urine osmolality was not significantly associated with water from other beverages or water from food in either sample.

\section{Relative odds of elevated urine osmolality by level of total water intake}

Table 2 describes the relative odds of elevated urine osmolality associated with a lower $v$. higher level of total 
Table 2 Relative odds of elevated urine osmolality by reported level of total water intake and source of water intake: healthy children aged 9-11 years in Los Angeles (LA) and New York City (NYC), spring 2009

\begin{tabular}{|c|c|c|c|c|c|c|c|c|c|}
\hline & \multirow[b]{3}{*}{$n$} & \multicolumn{2}{|c|}{ Urine osmolality } & \multicolumn{6}{|c|}{ Odds ratio } \\
\hline & & \multirow{2}{*}{$\frac{\leq 800 \mathrm{mmol} / \mathrm{kg}}{\%}$} & \multirow{2}{*}{$\frac{>800^{*} \mathrm{mmol} / \mathrm{kg}}{\%}$} & \multicolumn{2}{|c|}{ Unadjusted } & \multirow[b]{2}{*}{$P$} & \multicolumn{2}{|c|}{ Multivariable adjustedt } & \multirow[b]{2}{*}{$P$} \\
\hline & & & & OR & $95 \% \mathrm{Cl}$ & & OR & $95 \% \mathrm{Cl}$ & \\
\hline \multicolumn{10}{|l|}{ LA } \\
\hline \multicolumn{10}{|l|}{ Level of total water intake $(\mathrm{ml}) \ddagger$} \\
\hline Lower & 295 & 34 & 66 & $2 \cdot 8$ & $1 \cdot 5,5 \cdot 5$ & 0.002 & $2 \cdot 7$ & $1 \cdot 3,5 \cdot 6$ & 0.005 \\
\hline Higher\$ & 42 & 60 & 40 & $1 \cdot 0$ & & & $1 \cdot 0$ & 1,00 & 400 \\
\hline \multicolumn{10}{|l|}{ Source of water intake\| } \\
\hline Drinking water§ & 83 & 53 & 47 & $1 \cdot 0$ & & & $1 \cdot 0$ & & \\
\hline Water from other beverages & 171 & 34 & 66 & $2 \cdot 1$ & $1 \cdot 3,3 \cdot 7$ & 0.005 & $2 \cdot 1$ & $1 \cdot 2,3 \cdot 7$ & $0 \cdot 013$ \\
\hline Water from food only & 52 & 31 & 69 & $2 \cdot 8$ & $1 \cdot 3,5 \cdot 8$ & 0.007 & $2 \cdot 6$ & $1 \cdot 2,5 \cdot 6$ & $0 \cdot 017$ \\
\hline No water from food or beverages & 31 & 23 & 77 & $3 \cdot 2$ & $1 \cdot 3,8 \cdot 1$ & 0.012 & $2 \cdot 5$ & $0 \cdot 9,7 \cdot 3$ & 0.095 \\
\hline NYC & & & & & & & & & \\
\hline \multicolumn{10}{|l|}{ Level of total water intake $(\mathrm{ml}) \ddagger$} \\
\hline Lower & 179 & 33 & 67 & $1 \cdot 4$ & $0 \cdot 6,3 \cdot 0$ & $0 \cdot 401$ & 1.5 & $0 \cdot 6,3 \cdot 4$ & 0.380 \\
\hline Higher§ & 32 & 41 & 59 & $1 \cdot 0$ & & & $1 \cdot 0$ & & \\
\hline \multicolumn{10}{|l|}{ Source of water intakell } \\
\hline Drinking water§ & 58 & 43 & 57 & $1 \cdot 0$ & & & $1 \cdot 0$ & & \\
\hline Water from other beverages & 97 & 28 & 72 & $2 \cdot 0$ & $1 \cdot 0,3 \cdot 9$ & 0.053 & $2 \cdot 3$ & $1 \cdot 1,4 \cdot 8$ & 0.025 \\
\hline Water from food only & 42 & 36 & 64 & $1 \cdot 4$ & $0 \cdot 6,3 \cdot 1$ & 0.457 & 1.5 & $0 \cdot 6,3 \cdot 7$ & 0.334 \\
\hline No water from food or beverages & 14 & 36 & 64 & $1 \cdot 4$ & $0.4,4 \cdot 6$ & 0.616 & $1 \cdot 4$ & $0 \cdot 3,6 \cdot 1$ & 0.668 \\
\hline
\end{tabular}

*Urine osmolality $>800 \mathrm{mmol} / \mathrm{kg}$ is considered elevated ${ }^{(40,42,46)}$.

tThe odds ratio was adjusted for age, sex, general health, body weight, height, recent skin changes, use of medications, physical activity level, sleep in the $24 \mathrm{~h}$ before the urine sample, and the total energy intake and potential renal solute load on the morning of the urine sample.

fLower total water intake, $<500 \mathrm{ml}$; higher total water intake, $\geq 500 \mathrm{ml}$.

§Reference category in the logistic regression model.

IIStudy participants were grouped by the source of water intake. The 'drinking water' group reported intake of plain tap water, mineral, spring or unsweetened sparkling water, with or without intake of other beverages or food. The 'other beverages' group reported intake of beverages other than water. Specifically, they reported non-fat, $1 \%, 2 \%$ and whole milks; almond-, strawberry-, chocolate- and coffee-flavoured milks; smoothies; milkshakes; soya milk; orange, apple, cranberry, grape, pineapple, pomegranate, strawberry-banana and tomato juices; lemonade; sweetened teas; sports drinks; seltzer; and soda. The 'food only' group reported food, but no beverages. The 'no food or beverages' group did not eat or drink before the urine collection.

water intake. Elevated urine osmolality was significantly more likely in participants who reported a lower level of total water intake in the sample from LA, but not in the sample from NYC.

\section{Relative odds of elevated urine osmolality by source of water intake}

Table 2 describes the relative odds of elevated urine osmolality associated with the source of water. In both samples, after adjusting for all of the covariates listed above, participants who reported a beverage other than drinking water were two times more likely to have elevated urine osmolality than those who reported drinking water. In both samples, participants who did not report any drinking water (i.e. participants who reported another beverage, food only or no food or beverage, combined) were significantly more likely to have elevated urine osmolality than those who reported drinking water (adjusted $\mathrm{OR}=2 \cdot 2,95 \% \mathrm{CI} 1 \cdot 3,3 \cdot 7, P=0 \cdot 003$ in the LA sample and adjusted OR $=2 \cdot 0,95 \%$ CI $1 \cdot 0,3 \cdot 8, P=0 \cdot 045$ in the NYC sample).

\section{Mean urine osmolality by level of total water intake and source of water intake}

Not reporting drinking water was associated with higher urine osmolality, independent of a higher level of total water intake, in both samples (see Fig. 3). Participants who reported a total water intake of more than $500 \mathrm{ml}$, but no drinking water, had a mean urine osmolality above $800 \mathrm{mmol} / \mathrm{kg}$. Participants who reported more than $500 \mathrm{ml}$ total water intake, but included drinking water, had a mean urine osmolality below $800 \mathrm{mmol} / \mathrm{kg}$.

\section{Discussion}

The present study evaluated the urine osmolality of convenience samples of healthy children from two regions of the USA, in the mid-morning on a weekday under mild spring conditions, to explore whether hyperosmotic stress on cells might be a prevalent exposure in these samples. The study was motivated by recent studies in Israel $^{(40,41,46)}$ suggesting a high prevalence of elevated urine osmolality in healthy children due to diet.

Elevated urine osmolality was prevalent in both study samples. Approximately $60 \%$ of both samples had a urine osmolality above $800 \mathrm{mmol} / \mathrm{kg}$. The observed prevalence was similar to that reported for healthy children of the same age in Israel, at the same time of day, but under hot summer conditions ( $63 \%$ of children) ${ }^{(40)}$.

The reports from Israel attribute the elevated urine osmolality to poor drinking habits and/or involuntary dehydration, although water intake was not empirically assessed in those studies ${ }^{(40,46)}$. In the present study, urine 

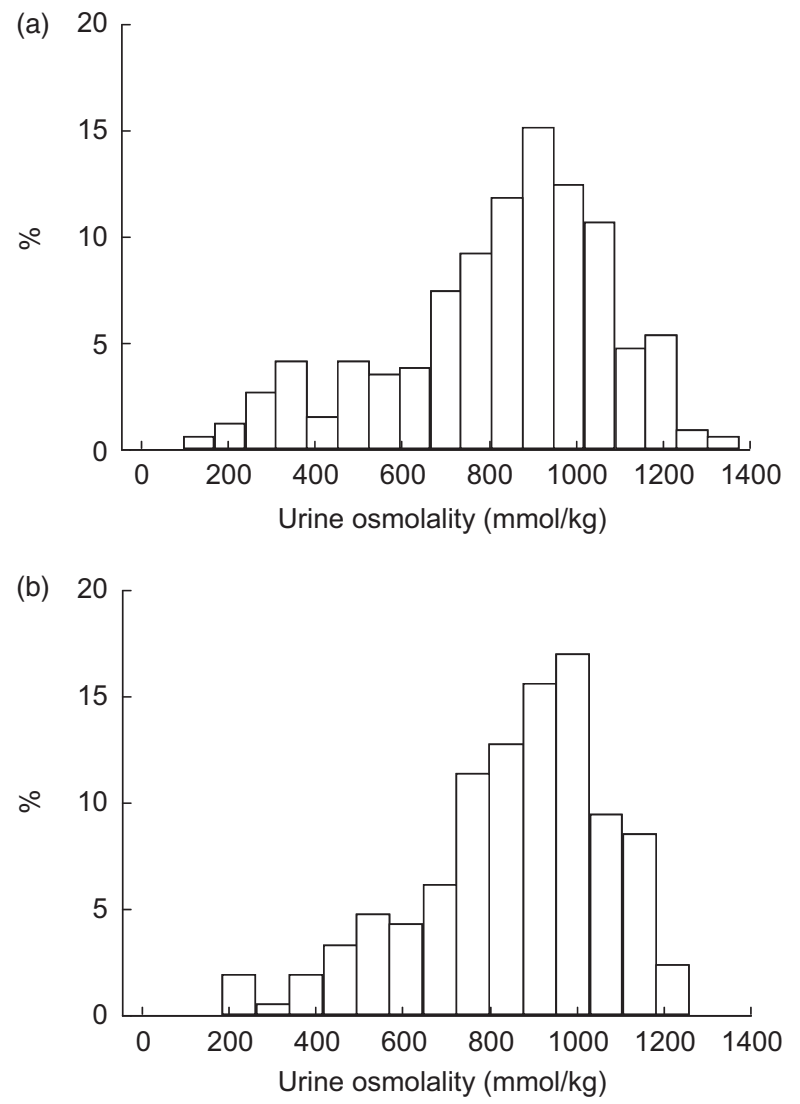

Fig. 1 Distribution of random morning urine osmolality of healthy children aged $9-11$ years in (a) Los Angeles ( $n$ 337) and (b) New York City ( $n$ 211), spring 2009

osmolality was evaluated together with dietary intake and other hydration determinants. Consistent with Bar-David et al.'s hypothesis, elevated urine osmolality was significantly associated with not drinking water.

Approximately $75 \%$ of the LA and NYC samples did not drink water before giving the urine sample. Given that a group mean provides an unbiased estimate of the 'usual' intake of the group, even if the group mean is calculated from only one diet record per individual ${ }^{(62)}$, this result suggests that, on any given weekday, $75 \%$ of these samples do not drink water before leaving the house.

The water intake data for the present study pertain to the window of time immediately prior to the urine sample, allowing temporality to be established, despite the cross-sectional design. The timing of these variables is important, because water intake and urine osmolality may be endogenously related, as cell shrinkage triggers both urine concentration and thirst.

In both the LA and NYC samples, elevated urine osmolality was specifically associated with not drinking water in the morning. More than $90 \%$ of both samples reported water intake from food or beverages before giving the urine sample. In both samples, even when the total amount of water was above $500 \mathrm{ml}$, water from other
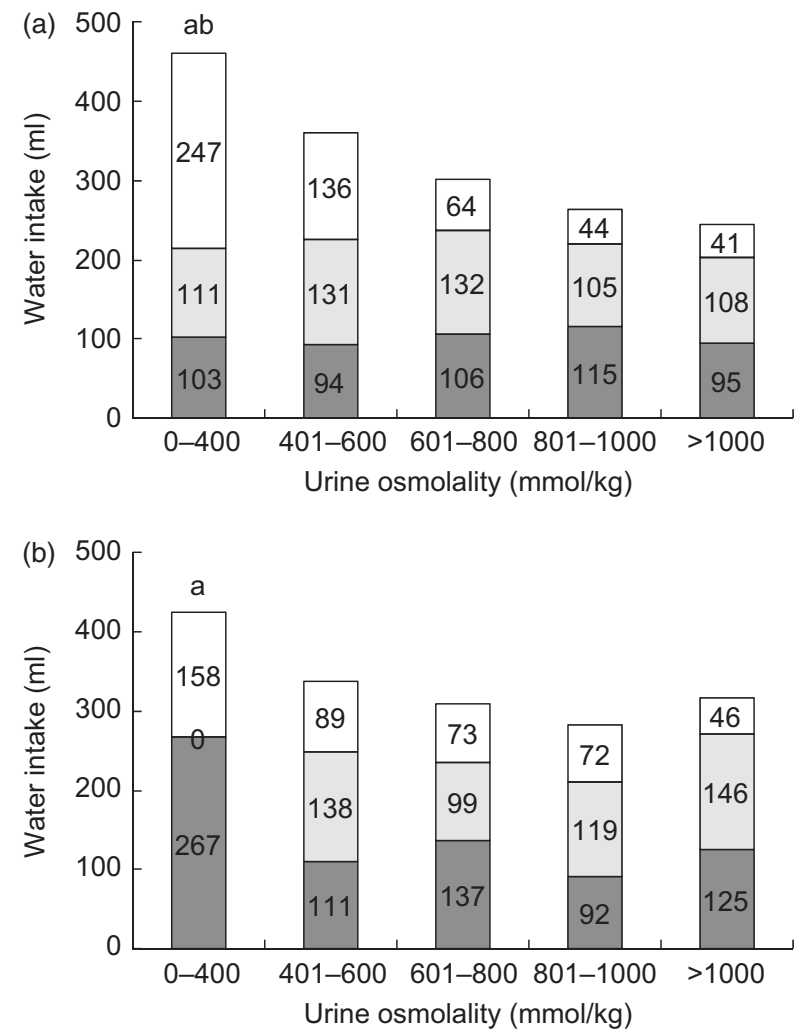

Fig. 2 Mean morning water intake by water source ( $\square$, drinking water; $\square$, water from other beverages; $\square$, water from food only) and level of urine osmolality in healthy children aged 9-11 years in (a) Los Angeles ( $n$ 337) and (b) New York City ( $n$ 211), spring 2009. Drinking water was defined as tap, spring, mineral or unsweetened sparkling water. Other beverages and food were defined following the Nutrition Data Systems (NDS-R) food group codes. Linear regression models were used to test for associations between urine osmolality and water intake, adjusting for age, sex, general health, body weight, height, recent skin changes, use of medications, physical activity level, sleep in the $24 \mathrm{~h}$ before the urine sample, and the total energy intake and potential renal solute load on the morning of the urine sample. aSignificant linear trend in drinking water $(P<0.05)$ after adjusting for covariates; ${ }^{b}$ significant linear trend in total water intake $(P<0.05)$ after adjusting for covariates

beverages was associated with elevated, not dilute, urine osmolality.

Acknowledging that the observed associations might be confounded by error from the diet record or covariates, it is nevertheless biologically plausible that beverages other than drinking water do not dilute urine like drinking water. Beverages other than drinking water are many-fold higher in osmolality than drinking water. Drinking water has an osmolality below the threshold for $\mathrm{ADH}$ release (about $3 \mathrm{mmol} / \mathrm{kg}$ ), whereas many other beverages and food have an osmolality above this threshold (e.g. milk: $300 \mathrm{mmol} / \mathrm{kg}$, orange juice: $600 \mathrm{mmol} / \mathrm{kg}$, cranberry juice: $1200 \mathrm{mmol} / \mathrm{kg})^{(63)}$. The levels of $\mathrm{Na}$, carbohydrate and amino acids in milk and juice can shrink cells and trigger $\mathrm{ADH}$ release ${ }^{(45,64,65)}$. While drinking water decreases urine osmolality in controlled experiments, hyperosmotic 

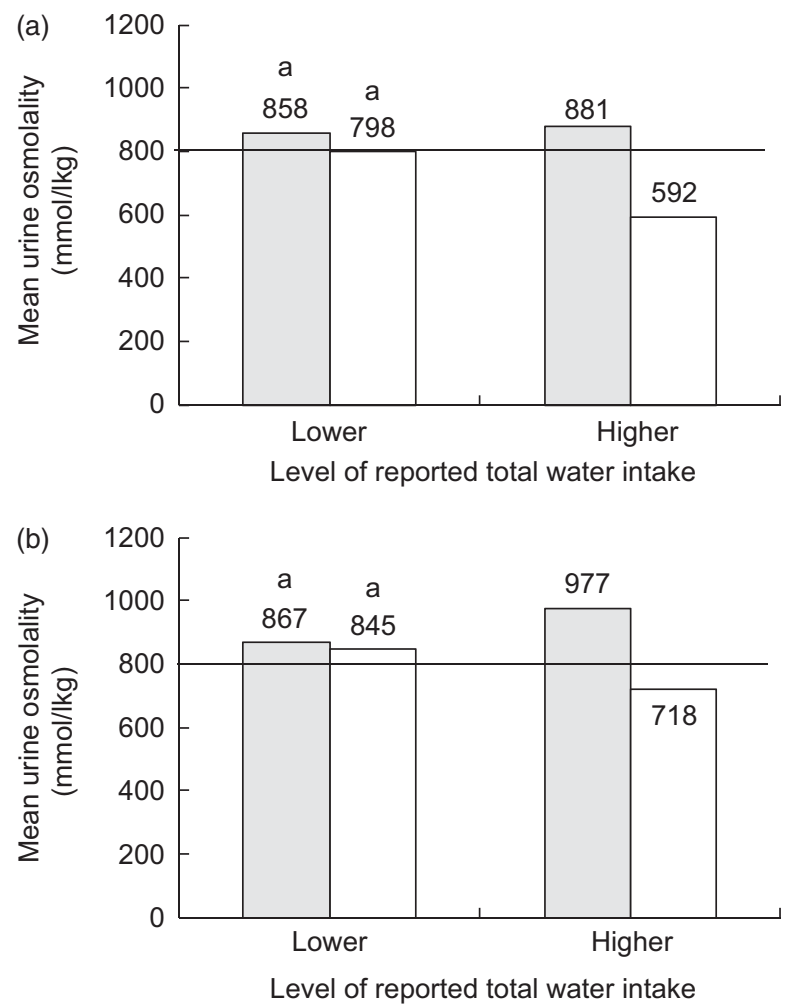

Fig. 3 Mean urine osmolality by level of total water intake among participants who reported no drinking water $(\square) v$. those who reported drinking water $(\square)$ : healthy children aged 9-11 years in (a) Los Angeles ( $n 337$ ) and (b) New York City ( $n 211)$, spring 2009. Lower $v$. higher level of total water intake was defined using a cut-off of $500 \mathrm{ml}$. Participants who reported drinking water reported any volume of plain tap, spring, mineral or unsweetened sparkling drinking water, with or without other

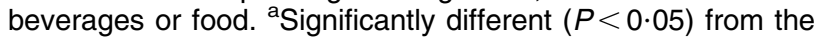
group that reported higher total water intake, including drinking water, adjusting for age, sex, general health, body weight, height, recent skin changes, use of medications, physical activity level, sleep in the $24 \mathrm{~h}$ before the urine sample, and the total energy intake and potential renal solute load on the morning of the urine sample. Urine osmolality values over $800 \mathrm{mmol} / \mathrm{kg}$ are considered elevated $(40,42,46)$

beverages and food increase urine osmolality ${ }^{(66-68)}$. An inverse association between urine osmolality and total water intake would not be expected, if total water intake primarily includes water from hyperosmotic sources.

Water from hyperosmotic sources is retained in the extracellular space unless or until changes in intracellular solute concentrations create a gradient that allows water redistribution into cells ${ }^{(44)}$. Hyperosmotic solutions have delayed absorption compared with drinking water ${ }^{(69)}$. Considering that water instantaneously follows osmotic gradients, a solution with a given osmotic load would not be expected to have the same effect as plain drinking water consumed separately and before an equivalent amount of solute. Timing may explain why drinking water was associated with lower odds of elevated urine osmolality in the present study, despite control for the morning osmotic load. An aggregate measure of osmotic load is not sensitive to the timing of solute intake relative to water intake.

The typical breakfast for children aged 8 to 10 years in Israel (a cup of chocolate milk with a few biscuits or a cup of milk with a handful of cornflakes ${ }^{(70)}$ ) is not unlike the breakfasts reported by the LA and NYC samples. It is possible that the elevated urine osmolality in Israel reflects a habit of not drinking water.

In the Israeli sample, children who arrived at school with elevated urine osmolality at 08.00 hours still had elevated urine osmolality at noon-time ${ }^{(40)}$. In the present study, it is not possible to know if the study participants eventually diluted their urine over the course of the day. Urine was collected at only one time point. Considering that access to drinking water may be limited in schools in the USA ${ }^{(52)}$ and that US children consume other beverages instead of drinking water ${ }^{(50)}$, it is conceivable that they did not dilute their urine. In Pittsburgh, fifty-eight out of 100 healthy children who collected $24 \mathrm{~h}$ urine samples (i.e. approximately $60 \%$ of the sample) had $24 \mathrm{~h}$ urine $\mathrm{Na}$ concentrations that exceeded the plasma $\mathrm{Na}$ concentration $^{(71)}$.

Even if the elevated urine osmolality eventually normalized with water intake later in the day, the results nevertheless suggest that $60 \%$ of these samples experience hyperosmotic stress on cells during the morning hours. Although a single urine sample may not reflect the 'usual' day-to-day status of an individual child, the aggregate data represent the 'usual' prevalence of elevated urine osmolality at that time of day in the LA and NYC samples.

The consequences of a 'usual' delayed urine dilution or greater time spent activating urine-concentrating mechanisms merit consideration, given the many effects of hyperosmotic stress on cells. Adaptive responses to cell dehydration are known to be metabolically expensive ${ }^{(72,73)}$. In Israel, elevated urine osmolality was associated with reduced cognitive performance at school ${ }^{(40)}$. If drinking water proves to be an important risk factor for cell hydration in schoolchildren, then drinking water campaigns and interventions may impact a wide array of health outcomes in children.

\section{Limitations}

The present cross-sectional study was limited by convenience sampling and self-reported measures. The results may not be generalizable to all US children. The participants may differ in unknown ways from children who did not participate. The associations in the study may be confounded by measurement error and/or incomplete control for confounding variables.

\section{Conclusions}

The present study reports a high prevalence of elevated urine osmolality in convenience samples of healthy freeliving children from LA and NYC at a time of day when 
they might normally be at school. Elevated urine osmolality was associated with not drinking water in both samples. Further work is warranted to confirm these results and consider the public health significance of hyperosmotic stress on cells for children in the USA.

\section{Acknowledgements}

The study was funded by an unrestricted grant from Nestec, Switzerland. J.D.S. has received unrestricted grants for other research projects from the sponsor. The other authors have no financial relationships with the sponsor. J.D.S was responsible for the project and involved in every stage from study design to manuscript preparation. B.B. and A.H. collected data and contributed to the manuscript preparation. A.A. contributed expertise to the study design and manuscript preparation.

\section{References}

1. Lang F, Busch GL, Ritter M et al. (1998) Functional significance of cell volume regulatory mechanisms. Physiol Rev 78, 247-306.

2. Andrew RD \& MacVicar BA (1994) Imaging cell volume changes and neuronal excitation in the hippocampal slice. Neuroscience 62, 371-383.

3. Eilers H \& Schumacher MA (2005) Mechanosensitivity of primary afferent nociceptors in the pain pathway. In Mechanosensitivity in Tissues and Cells, pp. 357-370 [A Kamkin and I Kiseleva, editors]. Moscow: Academia; available at http://www.ncbi.nlm.nih.gov/books/NBK7514/

4. Le Bihan D (2007) The 'wet mind': water and functional neuroimaging. Phys Med Biol 52, R57-R90.

5. Krause EG, deKloet AD, Flak JN et al. (2011) Hydration state controls stress responsiveness and social behavior. J Neurosci 31, 5470-5476.

6. Yancey PH, Clark ME, Hand SC et al. (1982) Living with water stress: evolution of osmolyte systems. Science 217, 1214-1222.

7. Haussinger D (2008) Osmosensing and osmosignaling in the liver. Wien Med Wochenschr 158, 549-552.

8. Hernanz-Schulman M, Vanholder R, Waterloos MA et al. (2000) Effect of radiographic contrast agents on leukocyte metabolic response. Pediatr Radiol 30, 361-368.

9. Lancaster MG \& Allison F (1966) Studies on the pathogenesis of acute inflammation. VII. The influence of osmolality upon the phagocytic and clumping activity by human leukocytes. Am J Pathol 49, 1185-1200.

10. Berneis K, Ninnis R, Haussinger D et al. (1999) Effects of hyper- and hypoosmolality on whole body protein and glucose kinetics in humans. Am J Physiol 276, E188-E195.

11. Brown CM, Barberini L, Dulloo AG et al. (2005) Cardiovascular responses to water drinking: does osmolality play a role? Am J Physiol Regul Integr Comp Physiol 289, R1687-R1692.

12. Capra NF \& Ro JY (2004) Human and animal experimental models of acute and chronic muscle pain: intramuscular algesic injection. Pain 110, 3-7.

13. Judelson DA, Maresh CM, Yamamoto LM et al. (2008) Effect of hydration state on resistance exercise-induced endocrine markers of anabolism, catabolism, and metabolism. J Appl Physiol 105, 816-824.
14. Lyall V, Heck GL, DeSimone JA et al. (1999) Effects of osmolarity on taste receptor cell size and function. Am J Physiol 277, C800-C813.

15. Pasantes-Morales H \& Tuz K (2006) Volume changes in neurons: hyperexcitability and neuronal death. Contrib Nephrol 152, 221-240.

16. Schliess F \& Haussinger D (2003) Cell volume and insulin signaling. Int Rev Cytol 225, 187-228.

17. McKenzie MA, Greenleaf JE, Looft-Wilson R et al. (1999) Leucocytosis, thrombocytosis, and plasma osmolality during rest and exercise: an hypothesis. J Physiol Pharmacol 50, 259-273.

18. Cheung SS \& McLellan TM (1998) Heat acclimation, aerobic fitness, and hydration effects on tolerance during uncompensable heat stress. J Appl Physiol 84, 1731-1739.

19. Ainslie PN, Campbell IT, Frayn KN et al. (2002) Energy balance, metabolism, hydration, and performance during strenuous hill walking: the effect of age. J Appl Physiol 93, 714-723.

20. Sawka MN (1992) Physiological consequences of hypohydration: exercise performance and thermoregulation. Med Sci Sports Exerc 24, 657-670.

21. Silnik M (1998) Practical management of diabetic ketoacidosis in childhood and adolescence. Paediatr Suppl $\mathbf{4 2 5}$, 63-66.

22. Trachtman H (1992) Cell volume regulation: a review of cerebral adaptive mechanisms and implications for clinical treatment of osmolal disturbances. Pediatr Nephrol 6, 104-112.

23. Vercellino M, Bezante GP \& Balbi M (2009) Contrast medium induced nephropathy: new insights into prevention and risk management. Cardiovasc Hematol Agents Med Chem 7, 166-180.

24. Pier GB (2002) CFTR mutations and host susceptibility to Pseudomonas aeruginosa lung infection. Curr Opin Microbiol 5, 81-86.

25. Kuroda T, Harada T, Tsutsumi H et al. (1997) Hypernatremic suppression of neutrophils. Burns 23, 338-340.

26. Platt OS (1982) Exercise-induced hemolysis in sickle cell anemia: shear sensitivity and erythrocyte dehydration. Blood 59, 1055-1060.

27. Tripette J, Loko G, Samb A et al. (2010) Effects of hydration and dehydration on blood rheology in sickle cell trait carriers during exercise. Am J Physiol Heart Circ Physiol 299, H908-H914.

28. El-Mougi M, Hendawi A, Koura H et al. (1996) Efficacy of standard glucose-based and reduced osmolarity maltodextrin-based oral rehydration solutions: effect of sugar malabsorption. Bull World Health Organ 74, 471-477.

29. Hahn S, Kim Y \& Garner P (2001) Reduced osmolarity oral rehydration solution for treating dehydration due to diarrhoea in children: systematic review. BMJ 323, 81-85.

30. Arora SK (2011) Hypernatremic disorders in the intensive care unit. J Intensive Care Med (Epublication ahead of print version).

31. Alshayeb HM, Showkat A, Babar F et al. (2011) Severe hypernatremia correction rate and mortality in hospitalized patients. Am J Med Sci 341, 356-360.

32. Stookey JD, Pieper CF \& Cohen HJ (2004) Hypertonic hyperglycemia progresses to diabetes faster than normotonic hyperglycemia. Eur J Epidemiol 19, 935-944.

33. Stookey JD, Purser JL, Pieper CF et al. (2004) Plasma hypertonicity: another marker of frailty? J Am Geriatr Soc 52, 1313-1320.

34. Kroke A, Manz F, Kersting M et al. (2004) The DONALD Study. History, current status and future perspectives. Eur J Nutr 43, 45-54.

35. Star RA (1990) Southwestern internal medicine conference: Hyperosmolar states. Am J Med Sci 300, 402-412. 
36. Manz F \& Wentz A (2003) 24-h hydration status: parameters, epidemiology and recommendations. Eur J Clin Nutr 57, Suppl. 2, S10-S18.

37. Edelmann Jr CM, Barnett HL, Stark H et al. (1967) A standardized test of renal concentrating capacity in children. Am J Dis Cbild 114, 639-644.

38. Manz F, Wentz A \& Sichert-Hellert W (2002) The most essential nutrient: defining the adequate intake of water. J Pediatr 141, 587-592.

39. Uttley WS, Paxton J \& Thistlethwaite D (1972) Urinary concentrating ability and growth failure in urinary tract disorders. Arch Dis Child 47, 436-441.

40. Bar-David Y, Urkin J \& Kozminsky E (2005) The effect of voluntary dehydration on cognitive functions of elementary school children. Acta Paediatr 94, 1667-1673.

41. Bar-David Y, Urkin J, Landau D et al. (2009) Voluntary dehydration among elementary school children residing in a hot arid environment. J Hum Nutr Diet 22, 455-460.

42. Philip M, Chaimovitz C, Singer A et al. (1993) Urine osmolality in nursery school children in a hot climate. Isr J Med Sci 29, 104-106.

43. Van Hoeck K, Bael A, Lax H et al. (2007) Circadian variation of voided volume in normal school-age children. Eur $J$ Pediatr 166, 579-584.

44. Nose H, Mack GW, Shi XR et al. (1988) Role of osmolality and plasma volume during rehydration in humans. $J$ Appl Physiol 65, 325-331.

45. Merson SJ, Maughan RJ \& Shirreffs SM (2008) Rehydration with drinks differing in sodium concentration and recovery from moderate exercise-induced hypohydration in man. Eur J Appl Physiol 103, 585-594.

46. Bar David Y, Landau D, Bar David Z et al. (1998) Urine osmolality among elementary school children living in a hot climate: implications for dehydration. Ambul Child Health 4, 393-397.

47. Bar-Or O (2001) Nutritional considerations for the child athlete. Can J Appl Physiol 26, Suppl., S186-S191.

48. D'Anci KE, Constant F \& Rosenberg IH (2006) Hydration and cognitive function in children. Nutr Rev 64, 457-464.

49. Stahl A, Kroke A, Bolzenius K et al. (2007) Relation between hydration status in children and their dietary profile - results from the DONALD study. Eur J Clin Nutr 61, 1386-1392.

50. Kant AK \& Graubard BI (2010) Contributors of water intake in US children and adolescents: associations with dietary and meal characteristics - National Health and Nutrition Examination Survey 2005-2006. Am J Clin Nutr 92, 887-896.

51. Chriqui JF, Schneider L, Chaloupka FJ et al. (2009) Local Wellness Policies: Assessing School District Strategies for Improving Children's Health. http://www.rwjf.org/files/ research/20090728bridgingthegapfull.pdf (accessed October 2011).

52. Patel AI, Bogart LM, Uyeda KE et al. (2010) Perceptions about availability and adequacy of drinking water in a large California school district. Prev Chronic Dis 7, A39.

53. Institute of Medicine (2004) Dietary Reference Intakes for Water, Potassium, Sodium, Chloride, and Sulfate. Washington, DC: The National Academies Press.
54. Bond L, Clements J, Bertalli N et al. (2006) A comparison of self-reported puberty using the Pubertal Development Scale and the Sexual Maturation Scale in a school-based epidemiologic survey. J Adolesc 29, 709-720.

55. Petersen AC, Crockett L, Richards M et al. (1988) A selfreport measure of pubertal status: reliability, validity and initial norms. I Youth Adolesc 17, 117-133.

56. Shirtcliff EA, Dahl RE \& Pollak SD (2009) Pubertal development: correspondence between hormonal and physical development. Child Dev 80, 327-337.

57. Ikeda Y, Tanaka I, Oki Y et al. (1993) Testosterone normalizes plasma vasopressin response to osmotic stimuli in men with hypogonadism. Endocr J 40, 387-392.

58. Stachenfeld NS (2008) Sex hormone effects on body fluid regulation. Exerc Sport Sci Rev 36, 152-159.

59. Weston AT, Petosa R \& Pate RR (1997) Validation of an instrument for measurement of physical activity in youth. Med Sci Sports Exerc 29, 138-143.

60. Welk GJ, Dzewaltowski DA \& Hill JL (2004) Comparison of the computerized ACTIVITYGRAM instrument and the previous day physical activity recall for assessing physical activity in children. Res Q Exerc Sport 75, 370-380.

61. Friis-Hansen B (1982) Water - the major nutrient. Acta Paediatr Scand Suppl 299, 11-16.

62. Guenther PM, Kott PS \& Carriquiry AL (1997) Development of an approach for estimating usual nutrient intake distributions at the population level. J Nutr 127, 1106-1112.

63. Mettler S, Rusch C \& Colombani PC (2006) Osmolality and $\mathrm{pH}$ of sport and other drinks available in Switzerland. Schweizerische Zeitschrift fur Sportmedizin und Sporttraumatologie 54, 92-95.

64. Arieff AI, Guisado R \& Lazarowitz VC (1977) Pathophysiology of Hyperosmolar States. Disturbances in Body Fluid Osmolality. Bethesda, MD: American Physiological Society.

65. Schmitt F, Bresson JL, Beressi N et al. (2003) Influence of plasma amino acid level on vasopressin secretion. Diab Metab 29, 352-361.

66. Seifert J, Harmon J \& DeClercq P (2006) Protein added to a sports drink improves fluid retention. Int J Sport Nutr Exerc Metab 16, 420-429.

67. Shirreffs SM, Aragon-Vargas LF, Keil M et al. (2007) Rehydration after exercise in the heat: a comparison of 4 commonly used drinks. Int J Sport Nutr Exerc Metab 17, 244-258.

68. Shirreffs SM, Watson P \& Maughan RJ (2007) Milk as an effective post-exercise rehydration drink. Br J Nutr $\mathbf{9 8}$, 173-180.

69. Vist GE \& Maughan RJ (1994) Gastric emptying of ingested solutions in man: effect of beverage glucose concentration. Med Sci Sports Exerc 26, 1269-1273.

70. Vaisman N, Voet H, Akivis A et al. (1996) Effect of breakfast timing on the cognitive functions of elementary school students. Arch Pediatr Adolesc Med 150, 1089-1092.

71. Moritz ML (2008) Urine sodium composition in ambulatory healthy children: hypotonic or isotonic? Pediatr Nephrol 23, 955-957.

72. Alfieri RR \& Petronini PG (2007) Hyperosmotic stress response: comparison with other cellular stresses. Pflugers Arch 454, 173-185.

73. O'Neill WC (1999) Physiological significance of volumeregulatory transporters. Am J Physiol 276, C995-C1011. 